\title{
Validation of the AASHTO LRFD Live Load Distribution Provisions for Integral Abutment Bridges
}

\author{
Sami W. Tabsh' ${ }^{1}$, Shehab El Din Mourad ${ }^{2}$ \\ ${ }^{1}$ American University of Sharjah \\ P.O. Box 26666, Sharjah, United Arab Emirates \\ stabsh@aus.edu \\ ${ }^{2}$ King Saud University \\ P.O Box 800, Riyadh 11421, Kingdom of Saudi Arabia \\ smourad@ksu.edu.sa
}

\begin{abstract}
Integral abutment bridges are structures that do not have discrete joints between the superstructure and substructure. Such bridges possess lower construction and maintenance costs, improved seismic performance, rapid construction procedures, and superior vehicular ride-ability. However, structural analysis of integral abutment bridges is not adequately covered in most bridge design specifications since the majority of the provisions address jointed structures. The purpose of this study is to check whether the current AASHTO LRFD bridge design specifications for live load effect are applicable to integral abutment bridges. To do so, typical single span monolithic bridges are models by finite elements with consideration of different girder spacing, free standing pile lengths and wingwall lengths. The girder distribution factors for flexure and shear from the finite element investigation are compared with the corresponding formulas in the specifications. The approach utilized by AASHTO to compute the flexural live load effect in the deck slab by considering a unit strip of the slab on rigid supports is checked against the finite element results. In general, findings of the study showed that the AASHTO specifications can be safely used to compute the load effect in girders and slabs of integral abutment bridges.
\end{abstract}

Keywords: Bridges, deck slab, finite element analysis, girder distribution factor, integral abutment, live load, steel girders.

\section{Introduction}

Around the world, there has been increased utilization of integral abutments in bridge construction in recent years. Such bridges have no joints between the monolithic superstructure and substructure, which enhances their economy, serviceability and strength [1]. Integral abutments are reinforced concrete structural systems consisting of a deep beam rigidly connected to two wing-walls and supported on one line of vertical piles, as shown in Fig. 1. For proper performance, some restrictions are imposed by bridge owners on the bridge total length, skew angle, and in-plane curvature. There are major differences between jointed and integral bridges. Most importantly, abutments supporting a disconnected superstructure are required resist lateral soil pressure on their own as free standing retaining walls, while integral abutments resist such pressure by shifting it to the superstructure above which acts as a compression member. The challenges associated with structural analysis, design and construction of integral abutment bridges exist because such structures are not adequately covered in the specifications and are greatly affected by creep, shrinkage and thermal effect.

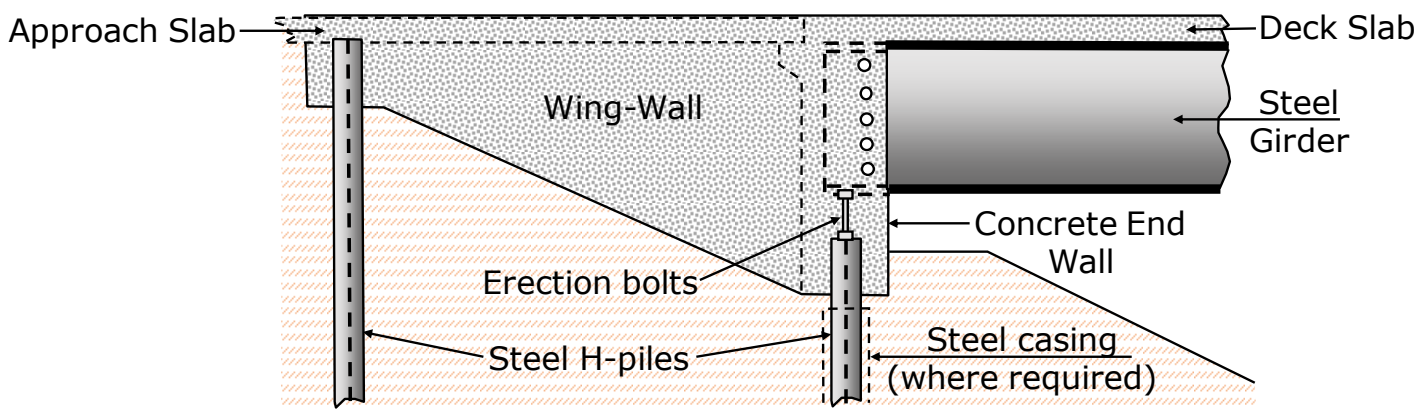

Fig. 1: Typical detail of integral abutment in a steel girder bridge. 
Previous research on the subject has mainly addressed thermal stresses [2-4], time-dependent effect [5-7], and seismic loading [8-10]. Little published work has considered live load [11-13], especially with regard to the applicability of current bridge design codes and specifications to integral bridges, which are based on jointed bridges for the most part. This paper aims to fill gap in that regard and checks whether the specifications' live load distribution provisions in one design standard can be used with reasonable accuracy to determine the load effect in single span integral abutment bridges in lieu of 3-dimensional finite element modelling.

\section{Problem Statement and Objectives}

Experience has shown that bridges that contain joints in the deck require continuous maintenance and rehabilitation because leaking salt-contaminated water from the superstructure causes corrosion damage in the supporting members underneath. By removing joints from bridges, such problem is eliminated. As a result, the economy of such bridges is enhanced due to the use of fewer piles, removal of bearings, abolition of expansion joints and diaphragms and utilization of non-battered piles. Although integral abutment bridges have been in use for some time, their coverage in bridge design specifications is limited. For example, the AASHTO LRFD Bridge Design Specifications [14] do not include girder distribution factors (GDF) specifically derived for integral bridges and do not address the structural analysis of deck slabs in such bridges near the abutments. Based on the above, the objectives of this study are to: (1) verify whether the GDF included in the AASHTO LRFD Specifications for flexure and shear are applicable to girders supported on integral abutments, and (2) validate the appropriateness of the approach used in the AASHTO LRFD Specifications for determining bending moments in one-way deck slabs in jointed bridges for integral bridges in the vicinity of the abutments. This study builds on the previous work on the subject by the two authors [15-17].

\section{Considered Structures}

Two composite steel girder bridges with integral abutments are considered in this study. They have the same bridge length $(25 \mathrm{~m})$, abutment wall dimensions ( $14 \mathrm{~m}$ long, $0.75 \mathrm{~m}$ thick, and $2.75 \mathrm{~m}$ thick), wing-wall dimensions ( $3.5 \mathrm{~m}$ long, $0.5 \mathrm{~m}$ thick, and 1-2.75 m non-prismatic depth), pile lengths ( $3 \mathrm{~m}$ under the abutment wall and $4.75 \mathrm{~m}$ under the wingwall's free end), roadway width $(13 \mathrm{~m})$, and material properties $\left(\mathrm{E}_{\mathrm{c}}=25 \mathrm{GPa}\right.$ and $\left.\mathrm{E}_{\mathrm{s}}=200 \mathrm{GPa}\right)$. They differ in concrete slab thickness (220 versus $200 \mathrm{~mm}$ ), size of steel girders (W920x416 versus W920x239), spacing of girders (3.5 versus $1.75 \mathrm{~m})$, deck overhang width $(1.75$ versus $0.875 \mathrm{~m})$, and number of HP300x79 supporting piles (11 versus 12 piles). The effects of changes in the pile length under the abutments $(\mathrm{L}=0,3$ and $6 \mathrm{~m})$ and wing-wall length $(\mathrm{H}=0,3.5$ and 7 $\mathrm{m})$ on the response are also considered in the study. The dimensions of the two considered bridges are shown in Fig. 2.

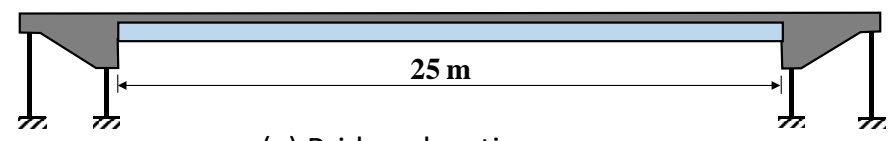

(a) Bridge elevation

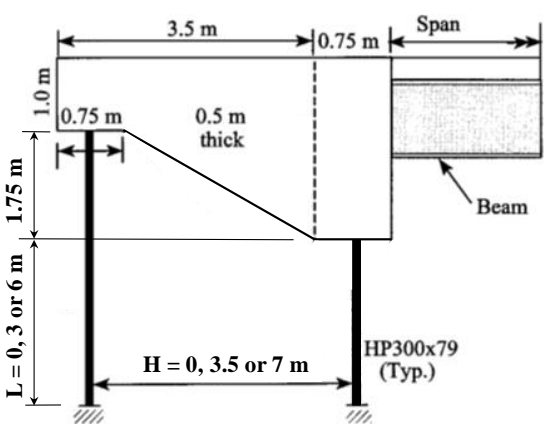

(b) Substructure

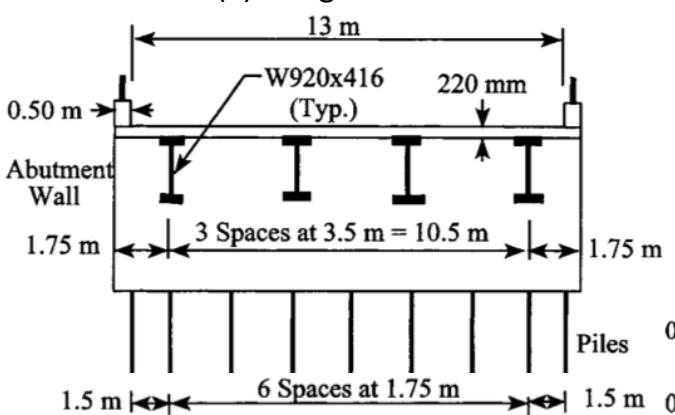

(c) Bridge 1 cross-section

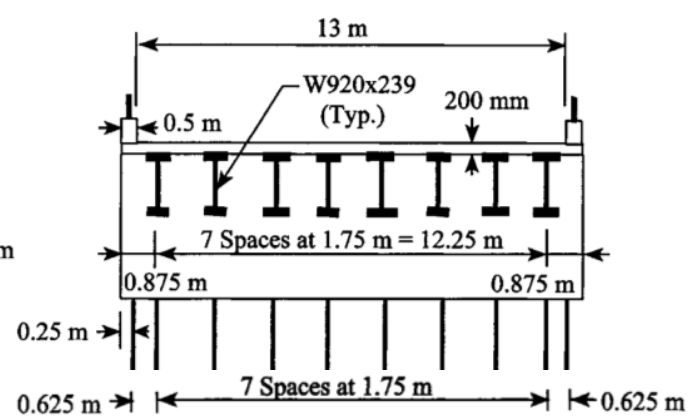

(d) Bridge 2 cross-section

Fig. 2: Geometry of bridges considered in the study. 


\section{Finite Element Modelling}

The integral bridges considered in this study are analysed by the finite element method within the linearly elastic range range following the validated approach first proposed by Tarhini and Federick [18]. Four-node shell elements are used to to model the deck slab and webs of the steel girders. Three-node shell elements are also used in the deck slab in the vicinity vicinity of the applied wheel loads. Eight-node solid elements are utilized in the wing-walls and abutment walls. The top and and bottom flanges of the steel girders as well as the cross-bracing members are modelled by 2-node beam elements. Rigid links are provided between the mid-depth of the deck slab and the centre of the top steel flanges. In lieu of considering the soil-structure interaction around the piles, 2-node beams elements are used to model the top portion of the piles, as free standing. The length of the piles is taken as the distance between the bottom of the substructure and the equivalent point of fixity within the soil. Such a length is a function of the soil profile and properties, applied loading and pile stiffness. It can be determined from the pile load-deflection relationships and is appropriate for use in an analysis that considers gravity loads because the piles are often driven at least $6 \mathrm{~m}$ into the soil, of which the top $3 \mathrm{~m}$ are within pre-augured holes to ensure unrestrained lateral pile movement under environmental load effect.

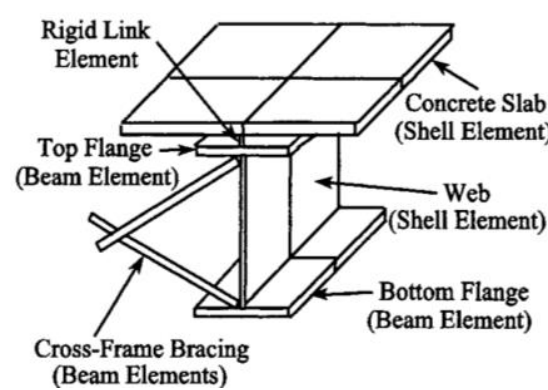

(a) Superstructure

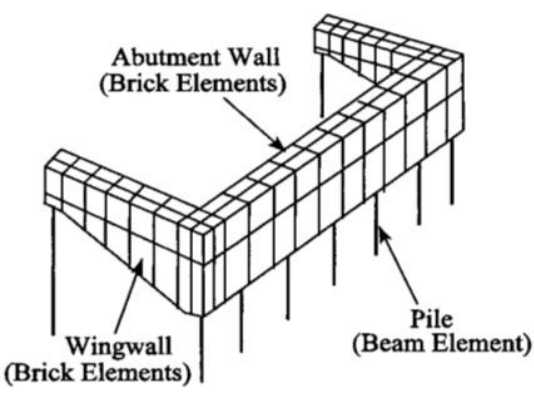

(b) Substructure

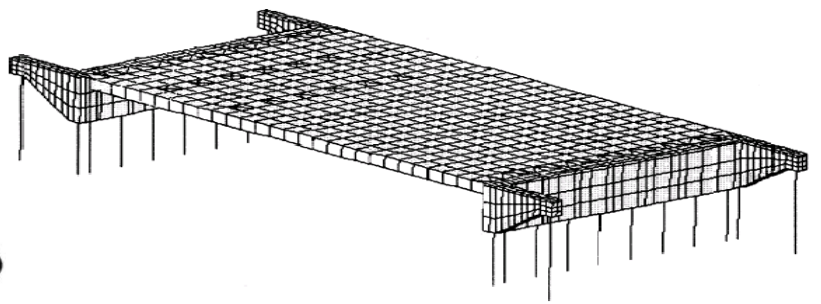

(c) Whole bridge

Fig. 3: Finite element model of the considered bridges.

To determine the girder distribution factor for flexure, $(\mathrm{GDF})_{\mathrm{f}}$, from the finite element results, the critical maximum tensile stresses in the top steel flanges due to one, two and three side-by-side HS20 trucks, shown in Fig. 4, are considered at the loaded abutment since in a linearly-elastic analysis the normal stress due to flexure is proportional to the moment:

$$
(G D F)_{f}=\frac{\mathrm{N} \mathrm{m} \mathrm{f}_{j}}{\sum_{i=1}^{n} \mathrm{f}_{i}}
$$

where $\mathrm{N}=$ number of loaded lanes, $\mathrm{m}=$ multiple presence factor (equal to 1.2 for one loaded lane, 1.0 for two loaded lanes, and 0.85 for three loaded lanes), $f_{j}=$ maximum normal stress in the top flange of the critical steel girder $j(\mathrm{MPa}), \mathrm{f}_{\mathrm{i}}=\operatorname{maximum}$ normal stress in the top flange of steel girder $\mathrm{i}(\mathrm{MPa})$, and $n=$ number of steel girders within the superstructure.

The corresponding girder distribution factor for shear, $(\mathrm{GDF})_{\mathrm{v}}$, from the finite element analysis is obtained by considering the maximum shear stress within the webs of the steel girders at the interface with the loaded abutment:

$$
(G D F)_{v}=\frac{\mathrm{N} \mathrm{m} \mathrm{v}_{j}}{\sum_{i=1}^{n} \mathrm{v}_{i}}
$$

where $v_{j}=$ maximum vertical shear stress in the web of the critical steel girder $\mathrm{j}(\mathrm{MPa})$ and $\mathrm{v}_{\mathrm{i}}=$ maximum shear stress in the web of steel girder i (MPa).

To compute the bending moment per unit strip in the deck slab, $\mathrm{M}$ (units: $\mathrm{N}-\mathrm{mm} / \mathrm{mm}$ ), from the finite element results, the normal stress in the slab is converted to bending moment through the flexure equation from mechanics of materials: 


$$
M=\frac{\sigma_{x}(1) \mathrm{t}^{2}}{6}
$$

in which $\sigma_{\mathrm{x}}=$ normal stress at the extreme top fibres of the slab along a direction perpendicular to the girders $(\mathrm{MPa})$ and $\mathrm{t}=$ the deck slab thickness (mm).
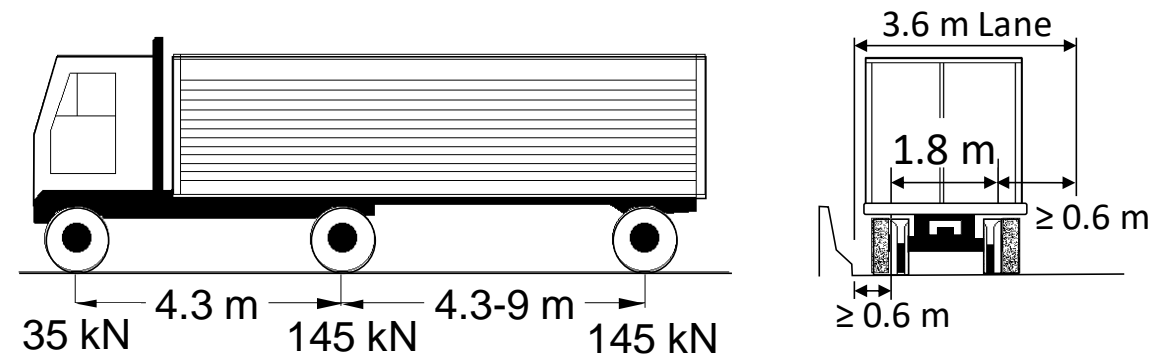

Fig. 4: HS20 truck configuration used in the finite element analysis.

\section{Results}

Results of the critical live load effect in the girders and deck slab from the finite element analysis of the two considered integral abutment bridges with their modifications with respect to the free standing pile length $(\mathrm{L}=0,3$ and $6 \mathrm{~m})$ and wing-wall length $(\mathrm{H}=0,3.5$ and $7 \mathrm{~m})$ are presented and compared with the relevant provisions in the latest edition of the AASHTO LRFD Bridge Design Specifications [14].

\section{1. Live Load Effect in Girders}

The AASHTO specifications include expressions of girder distribution factors that allow for the determination of the fraction of the live load effect carried by the most critical girder within the bridge when compared with the load effect due to the design truck. Such an approach replaces 3-dimensional modelling by 1-dimensional beam representation. For the case of flexure in an interior girder in a concrete slab-on-girders bridge subjected to multiple side-by-side trucks, the girder distribution factor, $(\mathrm{GDF})_{\mathrm{f}}$, is given by:

$$
(G D F)_{f}=0.075+\left(\frac{S}{2900}\right)^{0.6}\left(\frac{S}{L}\right)^{0.2}\left(\frac{K_{g}}{L t_{s}^{3}}\right)^{0.1}
$$

where $S=$ girder spacing $(\mathrm{mm}), \mathrm{L}=$ span length $(\mathrm{mm}), \mathrm{t}_{\mathrm{s}}=$ slab thickness $(\mathrm{mm})$, and $\mathrm{K}_{\mathrm{g}}=$ girder stiffness parameter $\left(\mathrm{mm}^{4}\right)$. The girder stiffness parameter is a function of the slab and girder geometric and material properties, obtained from:

$$
K_{g}=\frac{E_{s}}{E_{c}}\left(I+A e_{g}^{2}\right)
$$

in which $\mathrm{E}_{\mathrm{s}}=$ modulus of elasticity of the steel girder material $(\mathrm{MPa}), \mathrm{E}_{\mathrm{c}}=$ modulus of elasticity of the concrete deck slab material $(\mathrm{MPa}), \mathrm{I}=$ moment of inertia of the bare steel girder about a horizontal axis passing through its centroid $\left(\mathrm{mm}^{4}\right), \mathrm{A}$ $=$ cross-sectional area of the bare steel girder $\left(\mathrm{mm}^{2}\right)$, and $\mathrm{e}_{\mathrm{g}}=$ distance between the centroid of the steel girder and mid-depth of the slab (mm).

The corresponding AASHTO's girder distribution factor for the case of shear, $(\mathrm{GDF})_{\mathrm{v}}$, in an interior girder in a concrete slab-on-girders bridge subjected to multiple trucks is given by: 


$$
(G D F)_{v}=0.2+\left(\frac{S}{3600}\right)-\left(\frac{S}{10700}\right)^{2.0}
$$

Note that the above equations were derived based on detailed structural analysis of jointed bridges that are not built integral with the supports [19], and they include multiple truck presence factors. Substituting the relevant geometric and material properties of the considered integral abutment bridges in the above equations, one can get the girder distribution factors presented in Table 1.

Table 1: AASHTO's girder distribution factors for moment and shear for the considered bridges.

\begin{tabular}{|c|c|c|c|c|c|c|c|}
\hline Bridge & $\mathrm{S}(\mathrm{mm})$ & $\mathrm{L}(\mathrm{mm})$ & $\mathrm{t}_{\mathrm{s}}(\mathrm{mm})$ & Steel Beam & $\mathrm{K}_{\mathrm{g}}\left(\mathrm{mm}^{4}\right)$ & $(\mathrm{GDF})_{\mathrm{f}}$ & $(\mathrm{GDF})_{\mathrm{v}}$ \\
\hline 1 & 3500 & 25000 & 220 & $\mathrm{~W} 920 \times 416$ & $2.03 \times 10^{11}$ & 0.810 & 1.06 \\
\hline 2 & 1750 & 25000 & 200 & W920x239 & $1.08 \times 10^{11}$ & 0.483 & 0.659 \\
\hline
\end{tabular}

The maximum normal and shear stresses in the steel girders of Bridges 1 and 2, with their modifications concerning the pile and wing-wall lengths, from the finite element results are converted to girder distribution factors following the approach presented in the Section 4. The rear axles of the side-by-side HS20 trucks are placed on the bridges in the finite element analysis at $1 \mathrm{~m}$ away from the integral abutment. The girder distribution factors based on the maximum shear and negative bending moment in the most critical interior girder are compared with the results obtained from the AASHTO specifications and shown in Table 1. Figure 5a and 5b show the normalized results for Bridge 1 and Bridge 2, respectively. Note that in Fig. 5 when the free standing pile length is varied $(\mathrm{L}=0,3$ and $6 \mathrm{~m})$ the wing-wall length is kept constant at $3.5 \mathrm{~m}$. Likewise, when the wing-wall length is varied $(\mathrm{H}=0,3.5$ and $7 \mathrm{~m})$ the pile length is kept constant at $3 \mathrm{~m}$. The findings indicate that the AASHTO specifications over predict the shear in the interior girders in such bridges, especially when the girder spacing is small. They also show that the specifications can reasonably predict the flexural live load effect in the interior girders near the integral abutment for all the cases considered except for the two bridges that do not have wing-walls $(\mathrm{H}=0)$. The reason for this outcome is that such bridges have negligible negative bending moment in the girders at the abutment location due to the flexibility of the support which rests on one row of piles. Hence, such a case is not critical because the capacity of the girders when evaluated based on shear at the support and positive moment at mid-span will be more than adequate to resist such small negative bending moment in the girders at the abutments.

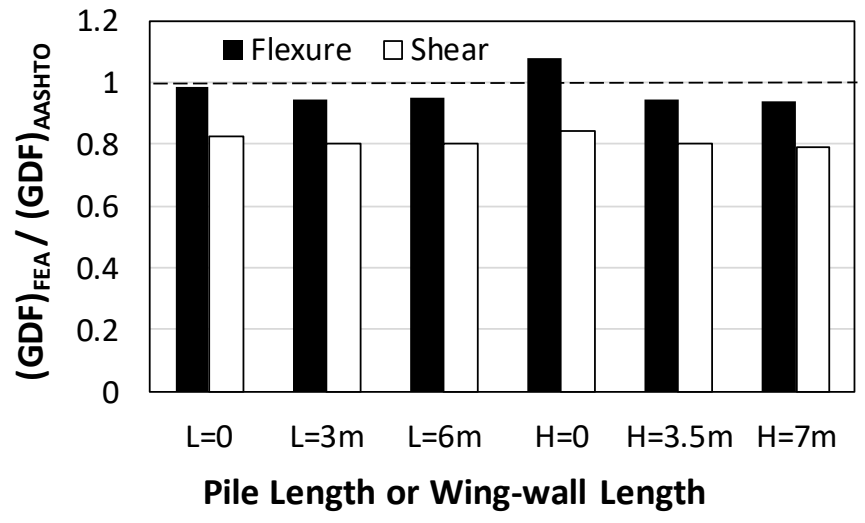

(a) Bridge 1

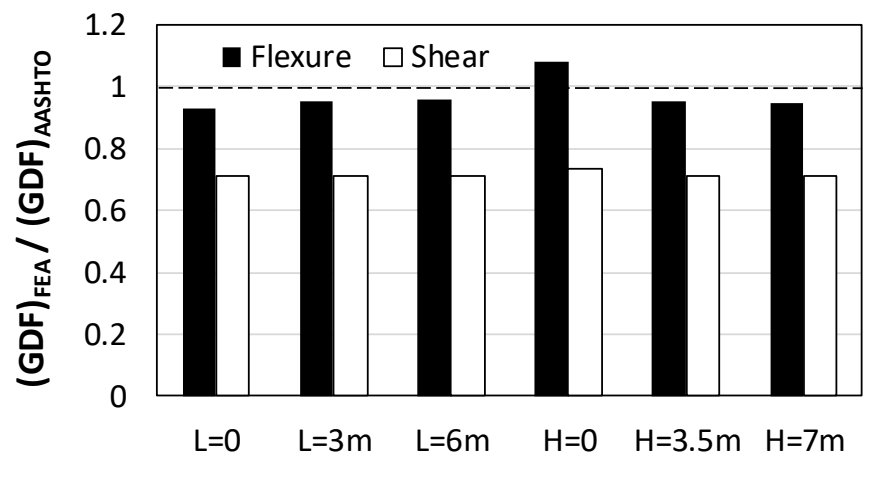

Pile Length or Wing-wall Length

(b) Bridge 2

Fig. 5: Comparison of live load effect in interior girders obtained by finite element analysis and AASHTO specifications. 


\section{2. Live Load Effect in Deck Slab}

According to the AASHTO LRFD specifications [14], structural analysis of the concrete deck slab in jointed bridges can be done by isolating a unit strip width of the concrete slab perpendicular to the centreline of the bridge at the location the heavy axles and treating the strip as a continuous beam on fixed supports. The axles should be placed on the strip the aid of influence lines so that maximum negative and positive bending moments are attained. In lieu of such an the specifications includes in an appendix tabulated values for envelopes of maximum positive and negative bending moments per unit strip of the slab for a wide range of girder spacing. For the two considered bridges in this study, the critical live load bending moments, without the dynamic load allowance, in the deck slab provided by AASHTO are shown in Table 2. Note that AASHTO allows the negative moment in the deck slab to be computed at a distance equal to one-quarter of the top flange length (i.e. $b_{f} / 4$ ) from the centreline of the steel girders. Also, shear in the deck slab is not considered the AASHTO specifications because experience has shown that such a load effect never governs; hence, it is not addressed in this study.

The maximum normal stresses in the transverse direction at the top of the deck slab of Bridges 1 and 2, with their modifications regarding the pile and wing-wall lengths, from the finite element results are converted to bending moments following the method presented at the end of Section 4. The rear axles of the side-by-side HS20 trucks are placed on the bridges in the finite element analysis at $1 \mathrm{~m}$ away from the integral abutment. The finite element results showed that the load effect in the deck slab is not greatly sensitive to variations in the free standing pile length or wing-wall length. As expected, they also indicated that there is a large two-way bending action in the deck slab in the vicinity of the integral abutment since the slab is integral with the abutment wall. Figure 6 shows the positive and negative bending moments in the transverse direction of the deck slab normalized with respect to the AASHTO results. As expected, the actual moments in the considered integral abutment bridges are much smaller than those predicted by AASHTO because the load in such bridges is distributed along two perpendicular directions, whereas the AASHTO approach is based on oneway load distribution. The finite element results also indicated large normal stresses in the deck slab along the longitudinal direction (i.e. along the bridge centreline), as a result of the negative bending moment in the composite steel girders near the integral abutments.

Table 2: AASHTO's maximum live load moment per unit width of slab for considered bridges.

\begin{tabular}{|c|c|c|c|c|}
\hline \multirow{2}{*}{$\begin{array}{c}\text { Bridge } \\
\text { No. }\end{array}$} & $\begin{array}{c}\text { Girder Spacing } \\
(\mathrm{mm})\end{array}$ & $\begin{array}{c}\text { Positive Moment } \\
(\mathrm{N}-\mathrm{mm} / \mathrm{mm})\end{array}$ & \multicolumn{2}{|c|}{ Negative Moment (N-mm/mm) } \\
\cline { 4 - 5 } & & & @ C-L of girder & @ $\mathrm{b}_{\mathrm{f}} / 4$ from C-L of girder \\
\hline 1 & 3500 & 26535 & 33053 & 28913 \\
\hline 2 & 1750 & 16252 & 15729 & 13519 \\
\hline
\end{tabular}

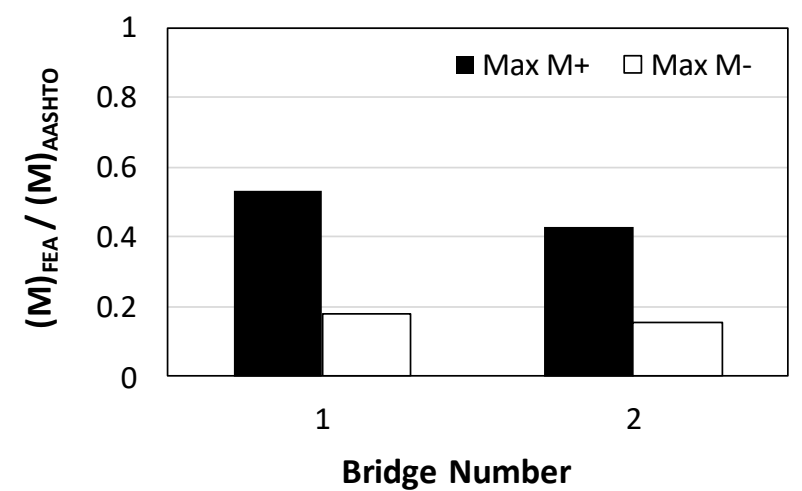

Fig. 6: Comparison of live load effect in deck slab obtained by finite element analysis and AASHTO specifications. 


\section{Summary and Conclusions}

Typical single span bridges with $25 \mathrm{~m}$ spans supported on integral abutments with wing-walls are modelled by finite elements with consideration of different girder spacing $(3.5$ and $1.75 \mathrm{~m})$, pile lengths $(0,3$ and $6 \mathrm{~m})$ and wing-wall lengths lengths $(0,3.5$ and $7 \mathrm{~m})$. The analysis uses shell elements in the deck slab and webs of the steel girders, solid elements in the in the wing-walls and abutment walls, and beam elements in the steel girders flanges, cross-bracing and piles. The girder distribution factors for flexure and shear in the interior girders from the finite element analysis are compared with the corresponding expressions provided by the AASHTO specifications. Furthermore, the approach utilized by AASHTO to compute the flexural live load effect in the deck slab by considering a unit strip width of the slab on rigid supports is checked against the finite element results. In general, results of this study leads to the following conclusions:

1. The AASHTO specifications can reasonably predict (within 7\%) the flexural live load effect due to negative bending in the interior girders near the integral abutment. It can slightly over predict (by up to 19\%) the shear in the interior girders in the considered bridges, especially when the girder spacing is small.

2. As expected, the finite element results showed that there is a large two-way bending action in the deck slab in the vicinity of the integral abutment, which reduces the transverse bending moment in the slab when compared with jointed bridges. Hence, the actual moments in the considered integral abutment bridges are much smaller than those predicted by the AASHTO specifications, especially for the negative bending moment. In addition to bending moment in the transverse direction, there are normal stresses in the deck slab along the longitudinal direction, as a result of the negative bending moment in the composite steel girders near the integral abutments.

\section{References}

[1] M. Arockiasamy, N. Butrieng and M. Sivakumar, "State-of-the-art of integral abutment bridges: design and practice," Journal of Bridge Engineering, vol. 9, no. 5, p. 497-506, September 2004.

[2] W-S Kim and J.A. Laman, "Integral abutment bridge response under thermal loading," Engineering Structures, vol. 32, no. 6, p. 1495-1508, June 2010.

[3] S. Albhaisi, H. Nassif, and E-S Hwang, "Effect of substructure stiffness on performance of steel integral abutment bridges under thermal loads," Transportation Research Record, no. 2313, p. 22-32, December 2012.

[4] J. M. Lafave, J. K. Riddle, M. W. Jarrett, B. A. Wright, Beth A., J. S. Svatora, H. An, and L. A. Fahnestock, "Numerical simulations of steel integral abutment bridges under thermal loading," Journal of Bridge Engineering, vol. 21, no. 10, October 2016.

[5] M. Arockiasamy and M. Sivakumar, "Time-dependent behavior of continuous composite integral abutment bridges," Practice Periodical on Structural Design and Construction, vol. 10, no. 3, p. 161-170, August 2005.

[6] J. Huang, C. K. Shield, and C. French, "Time-dependent behavior of a concrete integral abutment bridge," $6^{\text {th }}$ International Bridge Engineering Conference: Reliability, Security, and Sustainability in Bridge Engineering, p. 299309, 2005.

[7] K. Pugasap, W. Kim, and J. A. Laman, "Long-term response prediction of integral abutment bridges," Journal of Bridge Engineering, vol. 14, no. 2, p. 129-139, 2009.

[8] A. N. Kotsoglou, and S. J. Pantazopoulou, "Assessment and modelling of embankment participation in the seismic response of integral abutment bridges," Bulletin of Earthquake Engineering, vol. 7, no. 2, p. 343-361, May 2009.

[9] E. V. Monzon, A. M. Itani, and G. Pekcan, "Seismic behavior and design of steel girder bridges with integral abutments," Bridge Structures, vol. 10, no. 4, p. 117-128, 2014.

[10] S. Mahjoubi and S. Maleki, "Finite element modelling and seismic behaviour of integral abutment bridges considering soil-structure interaction," European Journal of Environmental and Civil Engineering, p. 1-20, January 2018.

[11] M. Dicleli and S. Erhan, "Effect of superstructure-abutment continuity on live load distribution in integral abutment bridge girders," Structural Engineering and Mechanics, vol. 34, no. 5, p. 635-662, March 2010.

[12] N. Nikravan and K. Sennah, "Parametric model on the CHBDC truck load distribution among girders in single-span integral abutment bridges," Proceedings of Annual Conference - Canadian Society for Civil Engineering, vol. 3, p. 2427-2436, January 2013. 
[13] O. F. Yalcin, "Comparative study of live load distribution in skewed integral and simply supported bridges," KSCE Journal of Civil Engineering, vol. 21, no. 3, p. 937-949, March 2017.

[14] AASHTO, LRFD bridge design specifications. American Association of State Highway and Transportation Officials, $8^{\text {th }}$ Edition, Washington D.C., 2017, 1781 p.

[15] S. W. Tabsh and S. Mourad, "Live load distribution in integral composite steel bridges," Engineering Journal, AISC, vol. 35, no. 1, pp. 12-18, March 1998.

[16] S. Mourad and S.W. Tabsh, "Pile forces in integral abutment bridges subjected to truck loads," Transportation Research Record, no. 1633, p. 77-83, Sep. 1998.

[17] S. Mourad and S. W. Tabsh, "Deck slab stresses in integral abutment bridges," Journal of Bridge Engineering, vol. 4, no. 2, p. 125-130, May 1999.

[18] K.M. Tarhini and G.R. Federick, "Wheel load distribution in I-girder highway bridges," Journal of Structural Engineering, ASCE, Vol. 118, No. 5, May 1992, p. 1285-1294.

[19] T. Zokaie, T. A. Osterkamp and R. A. Imbsen "Distribution of wheel loads on highway bridges," NCHRP Report 122611, Transportation Research Board, National Research Council, Washington D.C., 1991. 